OPEN ACCESS

Edited by:

Luca Rollè,

Università degli Studi di Torino, Italy

Reviewed by:

Abin Varghese,

Bhopal Memorial Hospital \& Research

Centre, India

Martina Smorti,

Università degli Studi di Pisa, Italy

*Correspondence:

Juliana Onwumere

juliana.1.onwumere@kcl.ac.uk

Specialty section:

This article was submitted to Gender, Sex and Sexuality Studies,

a section of the journal

Frontiers in Psychology

Received: 25 April 2018

Accepted: 02 August 2018

Published: 03 September 2018

Citation:

Onwumere J, Zhou Z and Kuipers E (2018) Informal Caregiving

Relationships in Psychosis: Reviewing the Impact of Patient Violence on

Caregivers. Front. Psychol. 9:1530.

doi: 10.3389/fpsyg.2018.01530

\section{Informal Caregiving Relationships in Psychosis: Reviewing the Impact of Patient Violence on Caregivers}

\author{
Juliana Onwumere ${ }^{1,2 *}$, Zheng Zhou ${ }^{1}$ and Elizabeth Kuipers ${ }^{1}$ \\ ${ }^{1}$ Department of Psychology, King's College London, Institute of Psychiatry, Psychology \& Neuroscience, London, \\ United Kingdom, ${ }^{2}$ Bethlem Royal Hospital, South London and Maudsley NHS Foundation Trust, Beckenham, \\ United Kingdom
}

A modest association can be found between people with a schizophrenia spectrum diagnosis (psychosis) and perpetrating acts of violence. When a person with psychosis does engage in violence, it is their informal carers, when compared to those from the general population, who are more likely to be the targets, and violence will often occur within the family home. Despite the importance of carer support for improving patient outcomes, our understanding of how carers are impacted by patient initiated violence in psychosis remains limited. This paper reviews literature documenting the effects of patient-initiated violence in psychosis on carer functioning. The review comprised searches of Medline, Psychlnfo, Embase, and Web of Science databases and the hand searches of reference lists from relevant published papers. The review was limited to English language publications from inception to 11th September 2017, and where carer experiences following reports of violence from patients with psychosis were specifically recorded. Data from 20 papers using mixed methodologies were reviewed. Patient violence in psychosis was linked to poorer carer outcomes, including carer reports of burden, trauma, fear, and helplessness. There is, however, a significant need for further studies to systematically quantify the impact and correlates of patient initiated violence on psychosis caregivers, and improve prevention.

Keywords: psychosis, violence, aggression, carers, families

His mother didn't want him to be reported to the police and I was sympathetic towards that. I decided we'd do it her way, and that was a mistake, it was mistake that she paid for.

(Ferriter \& Huband, 2003, p555)

\section{INTRODUCTION}

Schizophrenia spectrum disorders (psychosis) affect 7 per 1000 of the adult population with over 20 million people worldwide living with a diagnosis of schizophrenia alone (McGrath et al., 2008; World Health Organization, 2018). The disorders, with their first onset commonly occurring in young adulthood, are often long-term and highly burdensome (Whiteford et al., 2013). They are associated with a significantly reduced life expectancy (Hayes et al., 2017), stigma (Dickerson et al., 2002), and small social networks (Sündermann et al., 2014; Palumbo et al., 2015). Despite these challenges, many individuals with psychosis remain in close contact with informal carers from whom they receive valued support. Informal carers are a diverse group, but are mainly close 
family relatives (e.g., parents, partners, siblings) of patients and predominately female. The evidence base confirms that patients with carer support can achieve superior outcomes compared to peers without. The outcomes are varied but include significantly lower rates of relapse and overall number and length of psychiatric admissions (Norman et al., 2005), and improved rates of mortality (Revier et al., 2015; Ran et al., 2016) and service engagement (Stowkowy et al., 2012).

Though it has proved beneficial for improving patient outcomes, the caregiving role can impact negatively on carer health and wellbeing (Perlick et al., 2005; Flyckt et al., 2013; Gupta et al., 2015). Common mental disorders, including depression and anxiety, are significantly elevated in psychosis carers compared to the general population (Hayes et al., 2015). Carers also report experiencing exhaustion, grief reactions, and sleep disturbance (Patterson et al., 2005; Onwumere et al., 2017; Smith et al., 2018). As part of their role, many carers have also been exposed to episodes of anti-social behavior from the relatives they care for, these include episodes of both verbal and physical aggression (Belli et al., 2010; Onwumere et al., 2014).

\section{PSYCHOSIS AND VIOLENCE}

Societal concerns about mental health and violence will often peak in the aftermath of a reported random act of violence (e.g., homicide) committed by an individual with mental health problems. This tends to ensure that violence, and its risk assessment, remains an important issue for mental health professionals (Shopp, 1996). Contrary to common media stereotypes, people with psychosis are more likely to have a history of victimization experiences (Bebbington et al., 2004; Honings et al., 2017), including violent victimization (Dean et al., 2007a; Short et al., 2013; ten Have et al., 2014). They also have an elevated risk for self-harm (De Hert et al., 2001). However, people with psychosis are also more likely, than the general population, to perpetrate acts of violence, including homicide (Fazel et al., 2009; Short et al., 2013). The statistical association between violence and psychosis is frequently reported as modest (Coid et al., 2006; Taylor, 2008; Douglas et al., 2009; Fazel et al., 2009), and is particularly evident during the first psychosis episode (Nielssen et al., 2007; Spidel et al., 2010; Large and Nielssen, 2011), or in some studies, during the first year of problems (Meehan et al., 2006).

Data taken from a large scale study of first episode psychosis cases in England indicated that nearly $40 \%$ of patients were aggressive at first service contact and more than half were reported as being physically violent (Dean et al., 2007b). A systematic review and meta-regression analysis of first episode psychosis highlighted that $28 \%$ of patients were aggressive prior to service contact and $31 \%$ following contact with mental health services (Winsper et al., 2013). Similarly, as part of a smaller scale study of 34 adults attending a service for people with ultra-risk psychosis mental states, $38 \%$ were reported to have had a history of violent behavior (Hutton et al., 2012). Further, approximately one fifth of adolescents meeting diagnostic criteria for psychosis and attending a community based children and young person's psychiatric service in England were recorded as having a history of physical aggression (Khalid et al., 2012).

Parallel to investigating rates of violence in psychosis, much of the research attention in this area has also focused on identifying the purported risk factors and clinical correlates of patient violence (e.g., Swanson et al., 2006; Bo et al., 2011). For example, we know that patient violence in psychosis has been positively linked to several factors. These include: younger patient age (Dean et al., 2007b; Large and Nielssen, 2011; Coid et al., 2013); substance abuse (Coid et al., 2006; Fazel et al., 2010; Spidel et al., 2010); lower educational attainment (Large and Nielssen, 2011); poor vocational activity (Swanson et al., 2006), being from an ethnic minority group (Dean et al., 2007b; Coid et al., 2013), female gender (Swanson et al., 2006); male gender (Dean et al., 2007b); social difficulties (Amore et al., 2013); history of victimization (Swanson et al., 2006; Spidel et al., 2010), and patients with a forensic history (Large and Nielssen, 2011). Violence risk has also been linked to specific symptom clusters including mania (Dean et al., 2007b; Large and Nielssen, 2011); hallucinations (Swanson et al., 2006); delusional beliefs, particularly those related to persecution, being spied upon, and conspiracy (Joyal et al., 2011; Coid et al., 2013; Onwumere et al., 2016), or where the patient perceives personal threat and/or experiences thoughts that over-ride their sense of control (Chan, 2008; Nederlof et al., 2011). Disposition to anger (Nederlof et al., 2011), particularly where anger relates to delusional beliefs, is also linked to an increased risk of violence perpetration (Coid et al., 2013; Ullrich et al., 2013). Higher rates of violence are reported in individuals with untreated psychosis (Keers et al., 2014); before commencement of pharmacological treatments (Large and Nielssen, 2008; Nielssen and Large, 2010); in patients who are non-adherent with treatments (Witt et al., 2013), and in those with a history of involuntary and/or a greater number of psychiatric inpatient admissions (Large and Nielssen, 2011; Dack et al., 2013).

When we look at other factors, we know that positive links have also been observed between patient violence and coresidence with family members (Estroff et al., 1998; Swanson et al., 2006; Kageyama et al., 2015); poorer family relationships including patient reports of not feeling listened to by their family (Swanson et al., 2006), and attempts made by carers to establish behavioral limits with patients (Straznickas et al., 1993). A review of 4,168 patients with a diagnosis of schizophrenia suggested that patients, when compared to control groups, were more likely to come to the attention of police authorities through their involvement in family violence (Short et al., 2013). Further, in approximately one third of recorded adult domestic homicides in England and Wales, over an 11 year period, perpetrators were experiencing psychotic symptoms (Oram et al., 2013).

While only a relatively small proportion of the total global population will be diagnosed with a psychotic illness, and acts of violence vary in terms of context and severity, the importance of understanding the impact of violence on a victim has remained largely ignored in the psychosis caregiving literature (Solomon et al., 2005). This is despite the fact that this is another form of domestic violence or abuse. There is a paucity of data on 
reports of violence from patients with psychosis who have informal carers (Thompson, 2007), and scarce consideration of the implications for its assessment and management. The limited evidence base is surprising given the contribution to and importance of the caregiving role to patient outcomes in psychosis, and the large numbers of patients who live with or continue to remain in close contact with informal carers (The Schizophrenia Commission, 2012). Lifetime rates of carer exposure to patient violence varies but has been estimated in some studies to fall within the $50-60 \%$ range (e.g., Onwumere et al., 2014; Kageyama et al., 2015), with approximately one third of carers reporting incidents of violence in the preceding year (Kageyama et al., 2015). In addition, the risk factors associated with violence perpetration within the general population (e.g., substance misuse) are also elevated in psychosis populations (Hartz et al., 2014). Further, and perhaps most compelling, is the observation that carers, particularly those who are female and living with the patient (e.g., typically mothers), are more likely to be the identified target of violent acts compared to other family members and the general population (Nordström and Kullgren, 2003a,b; Nielssen et al., 2007; Belli et al., 2010; Ural et al., 2012). Carers are also more likely to sustain greater injuries (Nordström and Kullgren, 2003a). Whilst $\sim 8.4 \%$ of carers have issued legal orders (e.g., restraining orders) against the relatives they provide care for, following violence related issues (Solomon et al., 1995), the evidence suggests less likelihood of patient initiated violence directed toward carers ever being reported to law enforcement agencies (Nordström and Kullgren, 2003a).

\section{STUDY AIMS}

Patient initiated violence in psychosis is an important problem for many stakeholders including family members, who are the common victims. Interpersonal violence is a public health issue that exacts a significant impact on individual wellbeing (World Health Organization, 2002). Efforts to prevent violence in family settings must commence with a more comprehensive and informed understanding of the subjective experience and impact on victims. The current paper therefore aims to review the literature on the reported effects on carers who have been exposed to violence from patients with psychosis. It specifically seeks to address the research question: What are the reported effects of patient initiated violence on carers' physical and psychological wellbeing? The research and clinical implications will be discussed.

\section{METHOD AND TERMINOLOGY}

\section{Design}

A systematic review of the relevant literature with a qualitative synthesis of the findings.

\section{Search Criteria}

In accordance with the Preferred Reporting Items for Systematic Reviews and Meta-Analyses (PRISMA) statement (Moher et al., 2009), a search was undertaken of four electronic databases (Medline, PsychInfo, Embase and Web of Science) from inception to 11th September 2017. The search also included a hand search of the reference list of relevant papers to check for further applicable studies that had not been identified from the initial database review. The review was limited to: (i) studies where explicit links were reported between reports of patient initiated violence in psychosis and carer functioning; (ii) peer reviewed papers that were published in English language journals. Studies were excluded if they were review studies and those reporting data soley from non-psychosis patient populations (e.g., organic disorders like dementias), and/or psychosis conditions secondary to a primary disorder. Studies employing mixed diagnostic groups were excluded if psychotic disorders constituted $<30 \%$ of the sample.

Studies ineligible for inclusion were review studies, and those reporting data soley from non-psychosis patient populations (e.g., organic disorders like dementias) and/or psychosis conditions secondary to a primary disorder. Studies that employed mixed diagnostic groups were eligible for inclusion if psychotic disorders constituted at least $30 \%$ of the sample. Given the interchangeability in the use of terms to reflect violence (e.g., aggression) (O'Callaghan and Richman, 2010), we purposively included a broad definition of violence to account for any acts of aggression toward an individual or property, designed to threaten or inflict harm, irrespective of reported severity. A detailed list of keywords and Medical Subject Headings (MeSH) were used (with applicable search truncations and wild cards) to maximize the search capabilities and relevant paper selection. The selected terms and headings varied according to the specific database. Search terms related first to "psychosis" (serious mental illness OR severe mental disorder OR schizophren* OR schizo-affective, psychosis OR psychotic), "violence" (aggression OR violence OR abuse), and carers (caregiver* OR carer* OR famil* OR relative* OR parent* OR partner* OR spouse* OR sibling*). The Boolean operator "AND" was used to combine the three primary search term categories.

\section{Article Selection}

The titles and abstracts of identified articles from the initial search were screened, independently, by the first two authors against eligibility criteria and to remove duplicates. Selected papers were read against inclusion criteria. Disagreement between the reviewers about a decision to include or exclude were resolved through discussion. The study selection process is outlined in Figure 1. Data from the selected studies were tabulated and presented in terms of author, publication year, study design, sample, and summary of the key findings.

\section{RESULTS}

The initial search strategy identified 4,498 articles, which were reduced to 2,513, following exclusion of duplicates. Twenty papers met full criteria for selection. See Table $\mathbf{1}$ for summary of studies.

\section{Study Origin and Design}

The cited studies were international including six from Asia (Gopinath and Chaturvedi, 1992; Hanzawa et al., 2013; Hsu 

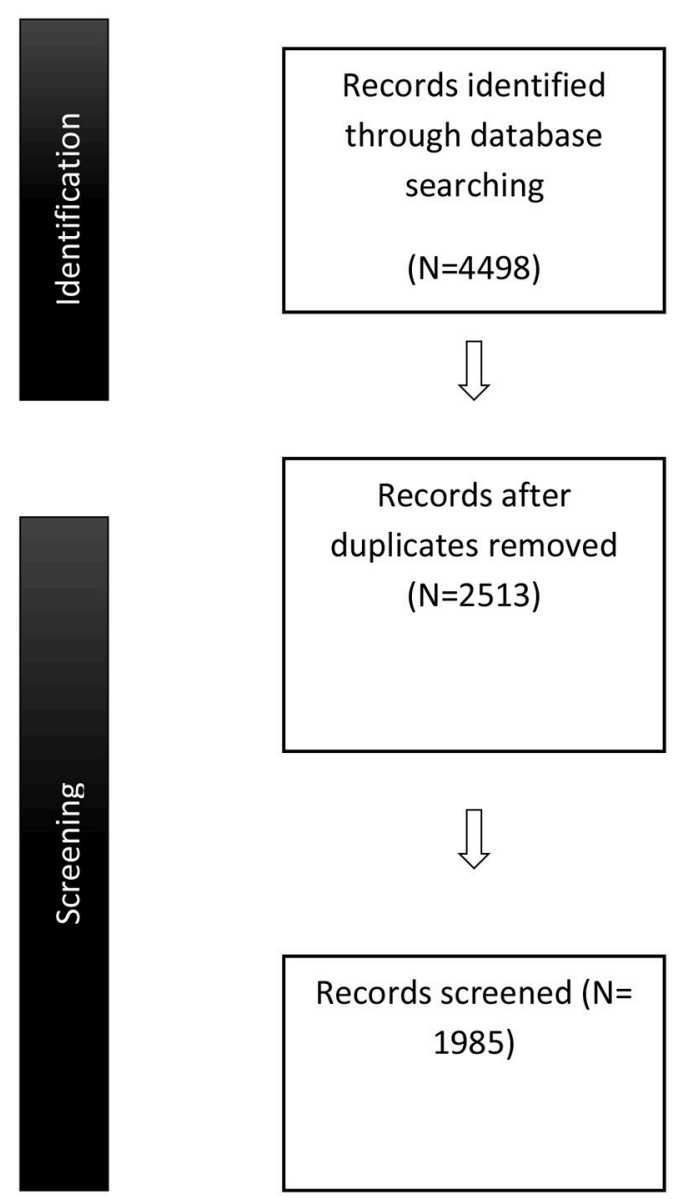

Records after duplicates removed $(\mathrm{N}=2513)$

Records screened $(\mathrm{N}=$ 1985)

Records excluded

$\sqrt{ }$ assessed for eligibility $(N=29)$

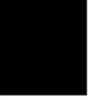

Full text articles<smiles>[C]=CC=C</smiles>

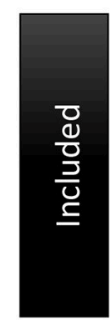

Studies included in qualitative synthesis

$(N=20)$
$(\mathrm{N}=1956)$

Full text articles excluded with reasons $(\mathrm{N}=9)$<smiles>C=C</smiles>
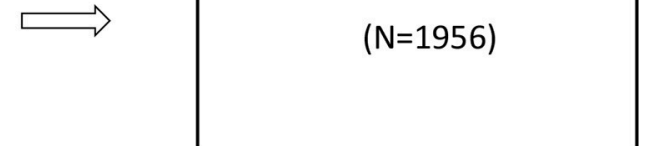

\section{- reporting on violence related} issues (e.g. risk) but not detailing impact on carer functioning $(\mathrm{N}=7)$

- theory/review paper $(\mathrm{N}=2)$ 
and Tu, 2013; Chaturvedi et al., 2014; Kageyama et al., 2016; Varghese et al., 2016); four from the USA (Friedrich et al., 1999; O'Brien et al., 2006; Thompson, 2007; Copeland and Heilemann, 2008); three from the United Kingdom (Gibbons et al., 1984; Ferriter and Huband, 2003; Onwumere et al., 2014) and Australia (Vaddadi et al., 1997, 2002; Loughland et al., 2009), and two from Sweden (Kjellin and Ostman, 2005; Nordström et al., 2006). The remaining studies had their origin in Canada (Chan, 2008) and Switzerland (Lauber et al., 2003). All studies, with exception of one, were cross sectional in design. The O'Brien et al. (2006) study was a 3 month longitudinal study.

\section{Carer Demography}

The total number of carer participants identified was 1,875 and most were female. In the 16 studies reporting this data, the composition of female participants in individual studies ranged from 39\% (Gopinath and Chaturvedi, 1992) to 100\% (Copeland and Heilemann, 2008). Only 65\% $(n=13)$ of studies offered details on the mean age of carer participants. Where details were offered, carer participants were aged mainly in their early to mid-50s (Vaddadi et al., 2002; Thompson, 2007; Chan, 2008; Loughland et al., 2009; Hanzawa et al., 2013; Onwumere et al., 2014) or 60s (Ferriter and Huband, 2003; Lauber et al., 2003; Kageyama et al., 2016). There were, however, carer participants who were notably younger with their mean ages falling in the mid-30s (Friedrich et al., 1999; Hsu and Tu, 2013) and 40s (Vaddadi et al., 1997; Varghese et al., 2016).

Carer participants were heterogeneous in how they related to patients, although most were reported as being the parents. The composition of parents in individual study samples ranged from 27\% (Kjellin and Ostman, 2005) to 100\% (Ferriter and Huband, 2003; Nordström et al., 2006; Copeland and Heilemann, 2008; Hsu and Tu, 2013; Kageyama et al., 2016).

Carer participants also included siblings, who were sampled in 10 studies (Gibbons et al., 1984; Friedrich et al., 1999; Kjellin and Ostman, 2005; O’Brien et al., 2006; Chan, 2008; Loughland et al., 2009; Hanzawa et al., 2013; Chaturvedi et al., 2014; Onwumere et al., 2014; Varghese et al., 2016), and partners, who were reported in 9 studies (Gibbons et al., 1984; Gopinath and Chaturvedi, 1992; Vaddadi et al., 1997, 2002; Kjellin and Ostman, 2005; Chan, 2008; Chaturvedi et al., 2014; Onwumere et al., 2014; Varghese et al., 2016). Carer participants who were the children of patients were included in six studies (Vaddadi et al., 2002; Kjellin and Ostman, 2005; Loughland et al., 2009; Hanzawa et al., 2013; Onwumere et al., 2014; Varghese et al., 2016).

\section{Patient Demography}

Homogeneous schizophrenia spectrum patient samples were employed in the majority of studies $(75 \%, n=15)$, with a further study using a psychosis prodrome sample (O’Brien et al., 2006). Only four studies employed mixed diagnostic samples where schizophrenia spectrum diagnoses ranged from one third (e.g., $31 \%$-Kjellin and Ostman, 2005) to $\sim 80 \%$ of the overall sample (e.g., 78\% Vaddadi et al., 2002). The additional diagnostic groups sampled were personality disorders, affective psychosis, bipolar affective disorder, and mood disorders (e.g., Vaddadi et al., 1997, 2002; Kjellin and Ostman, 2005; Thompson, 2007; Varghese et al., 2016).

\section{Clinical Setting}

Just over half of the studies sampled carers of patients who were living in community settings (Gibbons et al., 1984; Gopinath and Chaturvedi, 1992; Vaddadi et al., 2002; Lauber et al., 2003; O'Brien et al., 2006; Thompson, 2007; Chan, 2008; Copeland and Heilemann, 2008; Loughland et al., 2009; Chaturvedi et al., 2014; Kageyama et al., 2016). Inpatient only samples were used in five studies (Vaddadi et al., 1997; Ferriter and Huband, 2003; Kjellin and Ostman, 2005; Nordström et al., 2006; Hsu and Tu, 2013) and three studies used mixed inpatient and community dwelling groups (Hanzawa et al., 2013; Onwumere et al., 2014; Varghese et al., 2016). The study from Friedrich et al. (1999) did not offer any information on clinical setting.

\section{Assessment of Violence}

The operationalization of patient violence varied across studies. For example, in the Chan (2008) and Kageyama et al. (2016) studies, acts of physical, and psychological aggression were assessed. Three studies looked at acts of physical aggression only (Kjellin and Ostman, 2005; Nordström et al., 2006; Onwumere et al., 2014), with all remaining studies, but one, investigating verbal and physical aggression. It was unclear in the Copeland and Heilemann (2008) study whether verbal and/or psychological aggression was also included, in addition to physical aggression. The methods used to record data about patient violence varied considerably across studies and included patient medical records (e.g., Kjellin and Ostman, 2005; Thompson, 2007) and symptom rating scales (e.g., O’Brien et al., 2006); carer selfreport questionnaires (e.g., Nordström et al., 2006; Chan, 2008; Loughland et al., 2009; Hanzawa et al., 2013; Chaturvedi et al., 2014); carer semi-structured interviews (e.g., Vaddadi et al., 2002; Lauber et al., 2003; Copeland and Heilemann, 2008; Hsu and Tu, 2013; Onwumere et al., 2014), and combinations of the different assessment methods (e.g., Gibbons et al., 1984; Gopinath and Chaturvedi, 1992; Ferriter and Huband, 2003).

For the majority of studies, the assessment period focused on any episode of patient violence that had occurred since the initial illness onset (Gopinath and Chaturvedi, 1992; Ferriter and Huband, 2003; Lauber et al., 2003; Kjellin and Ostman, 2005; Hanzawa et al., 2013; Hsu and Tu, 2013). In three studies, the assessment review period was more limited and thus focused only on reports of violence that had taken place during the preceding 12 months (Chan, 2008; Loughland et al., 2009; Kageyama et al., 2016). Two studies focused on reports during the preceding 6 months (Varghese et al., 2016) or one month (Gibbons et al., 1984), while another prospectively measured violence over 3 months (O'Brien et al., 2006). A life time prevalence of patient violence was the focus in four studies (Vaddadi et al., 1997, 2002; Copeland and Heilemann, 2008; Onwumere et al., 2014). In addition to lifetime prevalence, Vaddadi et al. (2002) also recorded reports of violence in the last 12 months. Four studies did not share any information on the assessment period under study (Friedrich et al., 1999; Nordström et al., 2006; Thompson, 2007; Chaturvedi et al., 2014). 


\section{Impact of Patient Violence on Carer Functioning}

Fourteen studies reported a positive link between patient violence and reports of carer burden (Vaddadi et al., 1997, 2002; Friedrich et al., 1999; Ferriter and Huband, 2003; Lauber et al., 2003; Chan, 2008; Hanzawa et al., 2013; Chaturvedi et al., 2014) including financial burden (Thompson, 2007), and emotional distress (Gibbons et al., 1984; Vaddadi et al., 1997, 2002; Hsu and Tu, 2013; Kageyama et al., 2016). For example, Vaddadi et al. (2002), in a sample of 101 carers, identified a positive relationship between carer reports of emotional distress on the General Health Questionnaire (Goldberg and Williams, 1988) and patient aggression. Positive links between patient violence and trauma symptoms in carers were described in two studies (Loughland et al., 2009; Hanzawa et al., 2013). Hanzawa et al. (2013) observed that carers of patients who had been violent also reported significantly higher levels of intrusion, avoidance and hyperarousal symptoms on a self-report trauma measure (i.e., Impact of Event Scale-Revised, Weiss and Marmar, 1997; Asukai et al., 2002). In contrast, the findings from Gopinath and Chaturvedi (1992) suggested that it was patient difficulties with self-care, inactivity and depressed mood that carers reported as being most distressing and not patient aggression.

In five studies, carers reported experiencing fear (Nordström et al., 2006; Copeland and Heilemann, 2008; Hsu and Tu, 2013), which included beliefs that their life was in danger (Loughland et al., 2009) and a fear of violence recurrence in the future (Friedrich et al., 1999). Data from Hsu and Tu (2013) qualitative investigation suggested that patient violence led to carer reports of feeling powerless and frustrated over their perceived inability to control patient behavior and effect positive change. Carers described making a deliberate choice to remain quiet, out of fear that their relative might retaliate ( $\mathrm{Hsu}$ and $\mathrm{Tu}, 2013$ ).

Three studies observed positive links between patient violence and expressed emotion, which included carer reports of patient focused criticism (O'Brien et al., 2006; Chan, 2008); hostility (Onwumere et al., 2014), and emotional over involvement (intrusiveness) (Chan, 2008). In the Vaddadi et al. (2002), patient violence was associated with carers reporting a poorer relationship between the patient and themselves.

\section{DISCUSSION}

Despite the fact that carers can be integral to securing optimal outcomes for those with psychosis, violence, of any type, is likely to impact negatively on any family relationship. The importance of identifying and responding to carers' individual needs has now been recognized within several clinical treatment guidelines (NICE, 2014; Galletly et al., 2016; Norman et al., 2017). The current review suggests there have been few investigations that have purposively sought to directly and systematically record the outcomes for carers who have been exposed to patient violence in psychosis. Where outcomes have been identified, patient violence is seemingly linked to a wide range of negative carer outcomes that can include burden, emotional distress, fear, and high expressed emotion (EE).
These findings are offered against a body of literature which attests that poorer carer functioning and negative caregiving relationships; for example, high EE, are linked to patient poorer outcomes that include higher rates of relapse and hospitalization (Bebbington and Kuipers, 1994; Cechnicki et al., 2013; Hesse et al., 2015).

The current findings, which are based on a heterogenous group of studies, provide a useful template from which to explore, in greater detail, the carer experience of patient violence in psychosis. Though most carer participants surveyed were female, this picture is consistent with the profile of carers typically reported in psychosis research (e.g., Smallwood et al., 2017; Smith et al., 2018). In addition, the studies were diverse in country of origin and continent sampled, and their respective systems of health care provision (e.g., National Health Service; Health insurance).

It is noteworthy that the majority of studies reviewed had sampled carers at a single time point. The importance of this data should not be underestimated since it provides a much needed starting base to address pertinent questions on violence in caregiving relationships in psychosis. However, given the often repeat nature of violence, there is need to identify the potential longer-term implications of violence exposure for carer health, family outcomes, and service provision. For example, trauma presentations in carer groups are gradually receiving more research attention (Kingston et al., 2016). Exploring pathways between violence exposure, carer trauma reactions and coping styles (e.g., Loughland et al., 2009) would be beneficial and supported by multi time point studies.

Reports of patient violence toward caregivers are likely to be an underestimate, particularly when data are based upon selfreport, which can be influenced by issues of social desirability (Swanson et al., 2006). Stigma and efforts to avoid adversely affecting the care and public image of their relative are likely to impact carer willingness to disclose abuse in their relationship (Kageyama et al., 2015; Onwumere et al., 2016, 2018). Further research should aim to incorporate additional sources of data; for example, accident and emergency data. Likewise, future studies exploring patient violence in caregiving relationships should seek to assess its broader impact on carer functioning and relationships, and highlight potential pathways through which patient violence may disrupt these.

\section{LIMITATIONS}

The review was designed to offer a platform and direction for further studies but had key limitations. The selected studies tended to lack detailed information on carer participants such as weekly hours spent with patient, and the exact nature of their caregiving responsibilities; factors that could have provided more context to the findings. With exception of one, all studies were cross-sectional, thus precluding conclusions about causality. Few studies had solely set out to report on patient violence and its impact on carer outcomes, which limited the amount of data interrogation one could undertake. In accordance with the Cochrane Collaboration Tool for risk of bias (Higgins and 


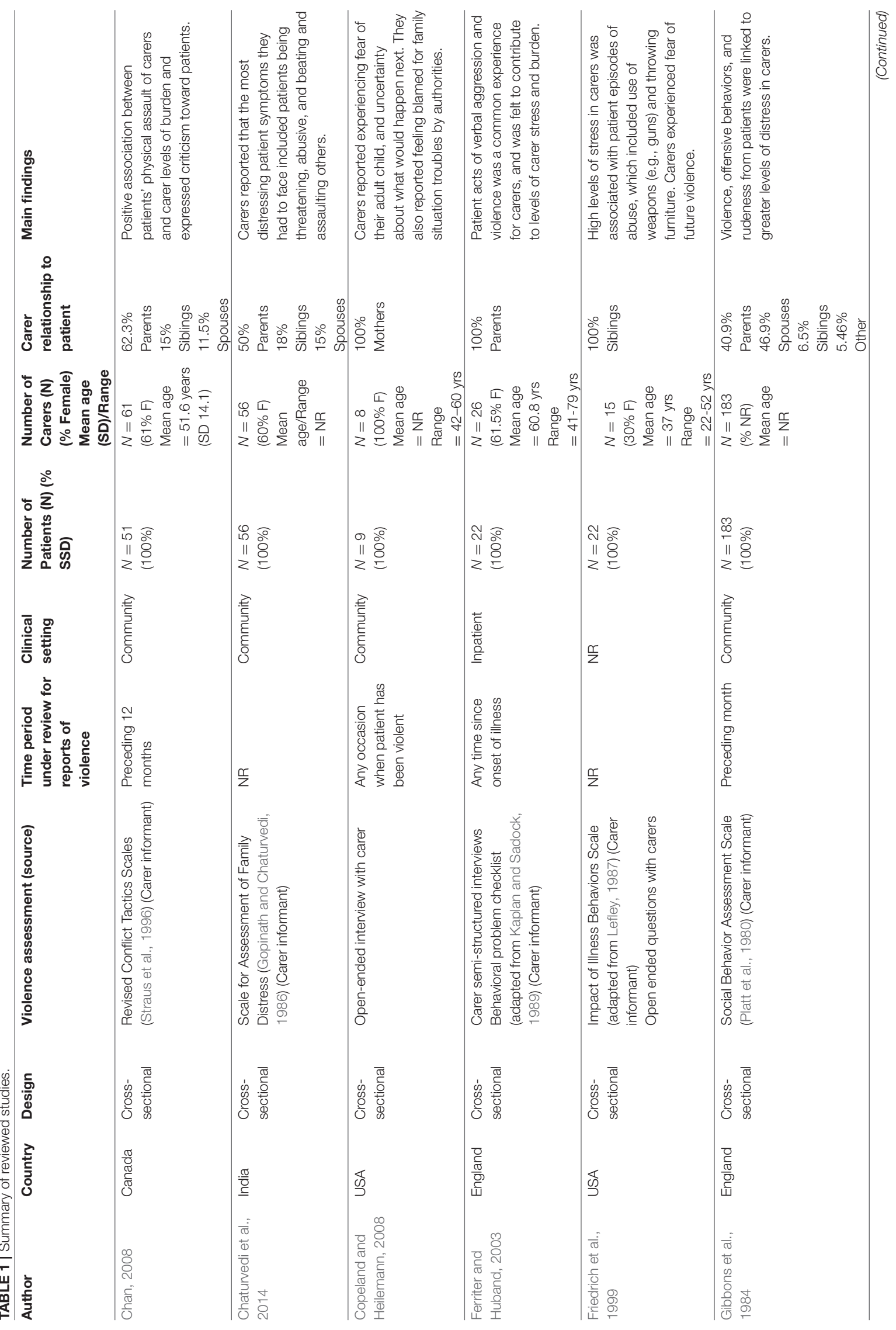




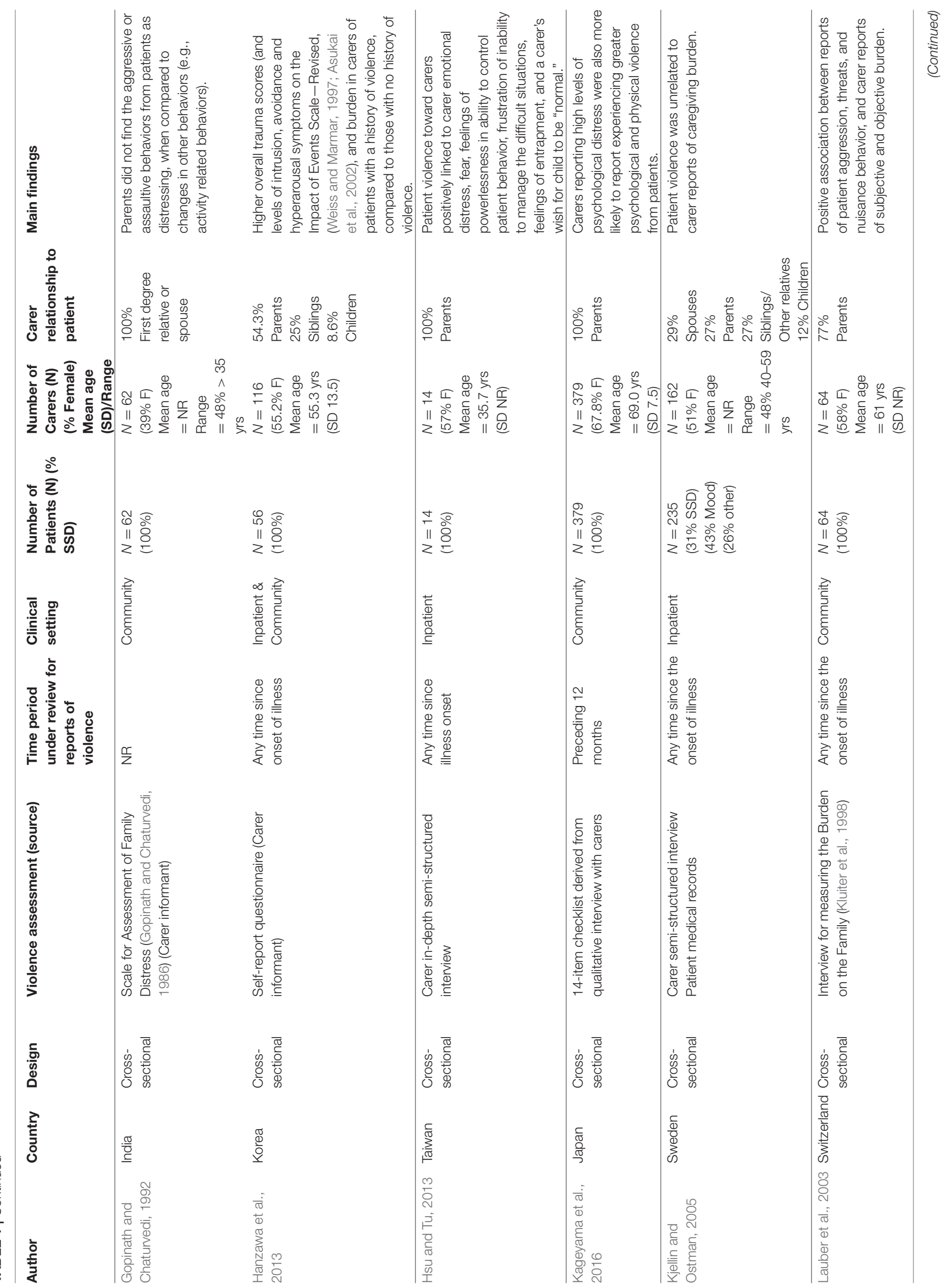




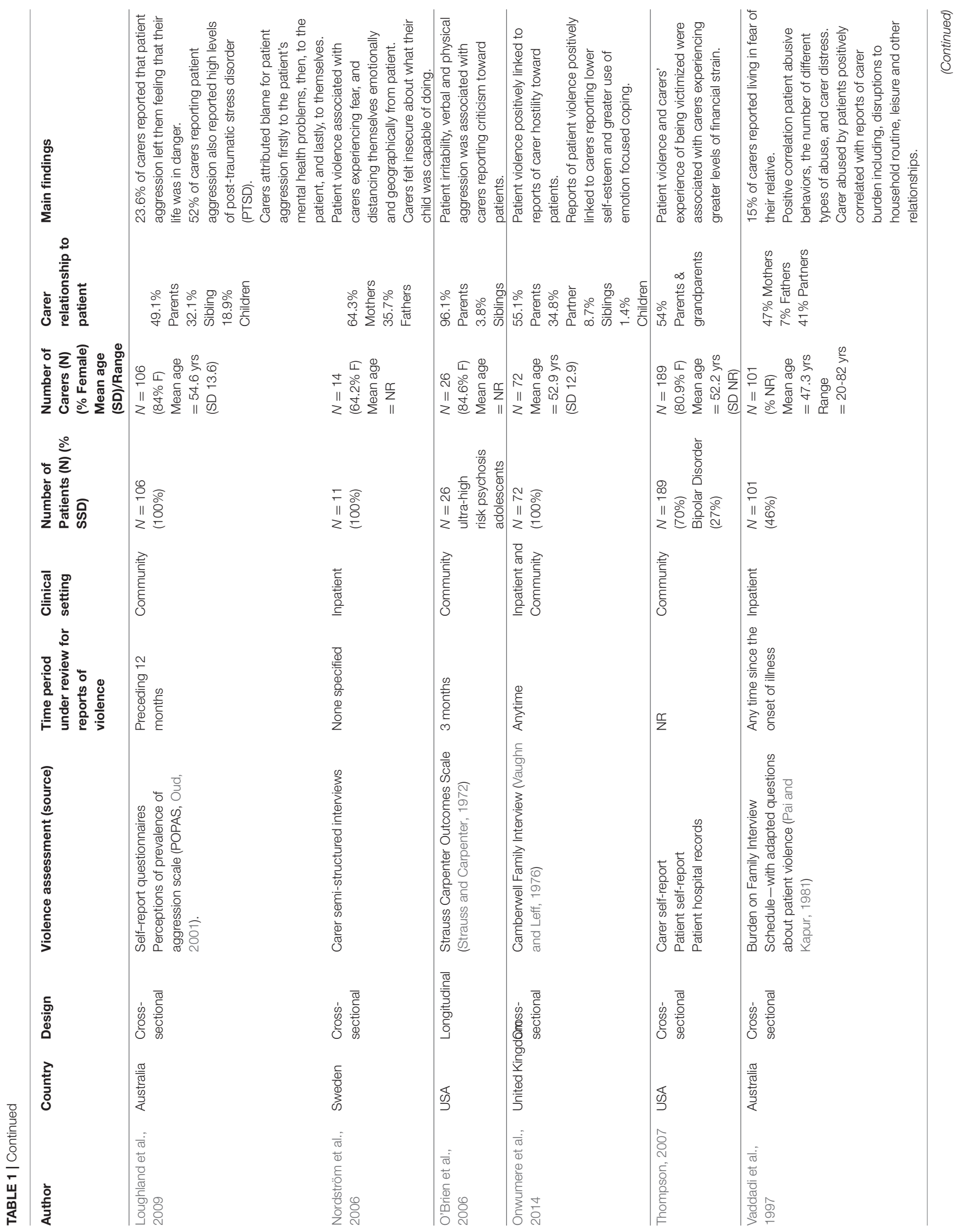







Altman, 2008), the studies were deemed at high risk for reporting bias due to homogeneity in methods used to record outcomes on carer impact (i.e., self-report). Finally, it is unclear to what extent the current findings are specific to psychosis caregivers or are observed in other severe mental health caregiver groups such as bipolar affective disorder. Future reviews may wish to extend the population group under study to include other diagnostic groups, which can help in the process of determining the scale of the problem and assessing the need for psychosis specific or trans-diagnostic responses.

\section{IMPLICATIONS}

The cognitive model of caregiving responses in psychosis highlights the importance of carer appraisals about the patient and the illness on overall outcomes (Kuipers et al., 2010). Though much has been written about issues of domestic violence and mental health (Howard, 2012), there has been a noticeable neglect of these issues when they are reported by informal carers of people with psychosis. For policy makers, greater awareness of the different family settings that interpersonal violence can and does occur, and the additional unique and complex needs faced by informal carers is required. A consideration of nuanced and targeted informant campaigns, specifically designed for those in caregiving roles and with an understanding of the broader issues should be given. More research is required to improve our understanding of the impact of patient violence on carer outcomes and the implications for their caregiving relationship. The data should help to facilitate the development of tailored interventions for carers and patients to help prevent such problems, minimize the risk of patient violence and the potential negative psychological and physical sequelae for carers. Recent findings from Bowman et al. (2014) suggest that the quality of life in the siblings of early psychosis patient groups can be negatively affected by a patient's history of violence. Thus, exploring the needs of other family members who may not be in primary caregiver roles but are nevertheless affected by patient violence would seem a helpful way forward. In services amongst clinicians,

\section{REFERENCES}

Amore, M., Tonti, C., Esposito, W., Baratta, S., Berardi, D., and Menchetti, M. (2013). Course and predictors of physical aggressive behaviour. Community Ment. Health J. 49, 451-456. doi: 10.1007/s10597-012-9530-1

Asukai, N., Kato, H., Kawamura, N., Kim, Y., Yamamoto, K., Kishimoto, J., et al. (2002). Reliability and validity of the Japanese-language version of the impact of event scale-revised (IES-R-J): four studies of different traumatic events. J. Nervous Ment. Dis. 190, 175-182. doi: 10.1097/00005053-200203000-00006

Bebbington, P., and Kuipers, L. (1994). The predictive utility of EE in schizophrenia: an aggregate analysis. Psychol. Med. 24, 707-718. doi: $10.1017 /$ S0033291700027860

Bebbington, P. E., Bhugra, D., Bhruga, T., Singleton, N., Farrell, M., Jenkins, R., et al. (2004). Psychosis, victimisation and childhood disadvantage. Br. J. Psychiatry 185, 220-226. doi: 10.1192/bjp.185.3.220

Belli, H., Ozcetin, A., Ertem, U., Tuyluoglu, E., Namli, M., Bayik, Y., et al. (2010). Perpetrators of homicide with schizophrenia: sociodemographic characteristics and clinical factors in the eastern region of Turkey. Compr. Psychiatry 51, 137-146. doi: 10.1016/j.comppsych.2009.03.006 more efforts are required to routinely and systematically record patient violence in caregiving relationships and its impact. Developing carer focused support interventions, which could be incorporated into community treatment models, are likely to benefit both carer and patient outcomes (McCann et al., 2011), and are consistent with recommended treatment approaches (NICE, 2014, 2015). Though most adults with psychotic disorders do not engage in violence, domestic violence in psychosis should be an issue of public health and concern. Focusing on building a better understanding of the patient sub groups who engage in acts of violence toward their caregivers might support the development of preventative and targeted interventions, which would have the potential to improve outcomes for all.

\section{CONCLUSION}

In psychosis, our findings indicate that patient violence in caregiving relationships can impact carer wellbeing and outcomes. Historically, however, carer needs and their issues have tended to be overlooked and marginalized. The current findings underscore the importance of focusing clinical and research efforts on carers and caregiving relationships affected by patient violence.

\section{AUTHOR CONTRIBUTIONS}

JO led on the conceptualization and design of the project. JO and ZZ led on the database searches and data synthesis. All authors contributed to preparing the manuscript.

\section{FUNDING}

For JO, this paper represents independent research partly funded by the National Institute for Health research (NIHR) Biomedical Research Centre at South London and the Maudsley NHS Foundation Trust and King's College London. The views expressed are those of the author(s) and not necessarily those of the NHS, the NIHR or the Department of Health.
Bo, S., Abu-Akel, A., Kongerslev, M., Haahr, U. H., and Simonsen, E. (2011). Risk factors for violence among patients with schizophrenia. Clin. Psychol. Rev. 31, 711-736. doi: 10.1016/j.cpr.2011.03.002

Bowman, S., Alvarez-Jimenez, M., Wade, D., Howie, L., and McGorrey, P. (2014). The impact of first episode psychosis on sibling quality of life. Soc. Psychiatry Psychiatr. Epidemiol. 49,1071-1081. doi: 10.1007/s00127-013-0817-5.

Cechnicki, A., Bielanska, A., Hanuszkiewicz, I., and Daren, A. (2013). The predictive validity of expressed emotions (EE) in schizophrenia. A 20-year prospective study. J. Psychiatr. Res. 47, 208-214. doi: 10.1016/j.jpsychires.2012.10.004.

Chan, B. W. Y. (2008). Violence against caregivers by relatives with schizophrenia. Int. J. Forensic Ment. Health. 7, 65-79. doi: 10.1080/14999013.2008.9914404

Chaturvedi, S. K., Hamza, A., and Sharma, M. P. (2014). Changes in distressing behaviour perceived by family of persons with schizophrenia at home--25 years later. Indian J. Psychol. Med. 36, 282-287. doi: 10.4103/0253-7176.135381

Coid, J., Yang, M., Roberts, A., Ullrich, S., Moran, P., Bebbington, P., et al. (2006). Violence and psychiatric morbidity in the national household population of Britain: public health implications. Br. J. Psychiatry 189, 12-19. doi: 10.1192/bjp.189.1.12 
Coid, J. W., Ullrich, S., Kallis, C., Keers, R., Barker, D., Cowden, F., et al. (2013). The relationship between delusions and violence. J. Am. Med. Assoc. 70, 465-471. doi: 10.1001/jamapsychiatry.2013.12

Copeland, D., and Heilemann, M. V. (2008). Getting "to the point": the experience of mothers getting assistance for their adult children who are violent and mentally ill. Nurs. Res. 57, 136-143. doi: 10.1097/01.NNR.0000319500.90240.d3

Dack, C., Ross, J., Papadopoulos, C., Stewart, D., and Bowers, L. (2013). A review and meta-analysis of the patient factors associated with psychiatric in-patient aggression. Acta Psychiatr. Scand. 127, 255-268. doi: 10.1111/acps.12053

De Hert, M., McKenzie, K., and Peuskens, J. (2001). Risk factors for suicide in young people suffering from schizophrenia: a long-term follow up study. Schizophr. Res. 47, 127-134. doi: 10.1016/S0920-9964(00)00003-7

Dean, K., Moran, P., Fahy, T., Tyrer, P., Leese, M., Creed, F., et al. (2007a). Predictors of violent victimization amongst those with psychosis Acta Psychiatrica Scandinavica 116, 345-353. doi: 10.1111/j.1600-0447.2007.01078.x

Dean, K., Walsh, E., Morgan, C., Demjaha, A., Dazzan, P., Morgan, K., et al. (2007b). Aggressive behaviour at first contact with services: findings from the AESOP first episode psychosis study. Psychol. Med. 37, 547-557. doi: 10.1017/S0033291706008920

Dickerson, F. B., Sommerville, J., Origoni, A. E., Norman, B., and Parente, F. (2002). Experiences of stigma among outpatients with schizophrenia. Schizophr. Bull. 28, 143-155. doi: 10.1093/oxfordjournals.schbul.a006917

Douglas, K. S., Guy, L. S., and Hart, S. D. (2009). Psychosis as a risk factor for violence to others: a meta-analysis. Psychol. Bull. 135, 679-686. doi: $10.1037 / \mathrm{a} 0016311$

Estroff, S. E., Swanson, J. W., Lachiotte, W. S., Swartz, M. S., and Bolduc, M. (1998). Risk reconsidered: targets of violence in social networks of people with serious psychiatric disorders. Soc. Psychiatry Psychiatr. Epidemiol. 33, 95-101. doi: 10.1007/s001270050216

Fazel, S., Buxrud, P., Ruchkin, V., and Grann, M. (2010). Homicide in discharged patients with schizophrenia and other psychoses: a national case-control study. Schizophr. Res. 123, 263-269. doi: 10.1016/j.schres.2010.08.019

Fazel, S., Långström, N., Hjern, A., Grann, M., and Lichtenstein, P. (2009). Schizophrenia, substance abuse, and violent crime. J. Am. Med. Assoc. 301, 2016-2023. doi: 10.1001/jama.2009.675

Ferriter, M., and Huband, N. (2003). Experiences of parents with a son or daughter suffering from schizophrenia. J. Psychiatr. Ment. Health Nurs. 10, 552-560. doi: 10.1046/j.1365-2850.2003.00624.x

Flyckt, L., Lothman, A., Jorgensen, L., Rylander, A., and Koernig, T. (2013). Burden of informal care giving to patients with psychoses: a descriptive and methodological study. Int. J. Soc. Psychiatry 59, 137-146. doi: $10.1177 / 0020764011427239$

Friedrich, R. M., Lively, S., and Buckwalter, K. C. (1999). Well siblings living with schizophrenia. Impact of associated behaviors. J. Psychosoc. Nurs. Ment. Health Serv. 37, 11-19.

Galletly, C., Castle, D., Dark, F., Humberstone, V., Jablensky, A., Killackey, E., et al. (2016). Royal Australian and New Zealand College of Psychiatrists clinical practice guidelines for the management of schizophrenia and related disorders. Aust. N. Z. J. Psychiatry 50, 410-472. doi: 10.1177/0004867416641195

Gibbons, J. S., Horn, S. H., Powell, J. M., and Gibbons, J. L. (1984). Schizophrenic patients and their families. A survey in a psychiatric service based on a DGH unit. Br. J. Psychiatry 144, 70-77. doi: 10.1192/bjp.144.1.70

Goldberg, D., and Williams, P. (1988). A Users' Guide to the General Health Questionnaire. Windsor, ON: NFER-Nelson.

Gopinath, P. S., and Chaturvedi, S. K. (1986). Measurement of distressful psychotic symptoms perceived by the family: preliminary findings. Indian J. Psychiatry 28, 343-345.

Gopinath, P. S., and Chaturvedi, S. K. (1992). Distressing behaviour of schizophrenics at home. Acta Psychiatrica Scandinavica 86, 185-188. doi: 10.1111/j.1600-0447.1992.tb03249.x

Gupta, S., Isherwood, G., Jones, K., and Van Impe, K. (2015). Assessing health status in informal schizophrenia caregivers compared with health status in non-caregivers and caregivers of other conditions. BMC Psychiatry 15:162. doi: 10.1186/s12888-015-0547-1

Hanzawa, S., Bae, J. K., Bae, Y. J., Chae, M. H., Tanaka, H., Nakane, H., et al. (2013). Psychological impact on caregivers traumatized by the violent behavior of a family member with schizophrenia. Asian J. Psychiatr. 6, 46-51. doi: 10.1016/j.ajp.2012.08.009
Hartz, S. M., Pato, C. N., Medeiros, H., Cavazos-Rehg, P., Sobell, J. L., Knowles, J. A., et al. (2014). Comorbidity of severe psychotic disorders with measures of substance use. J. Am. Med. Assoc. 71, 248-254. doi: 10.1001/jamapsychiatry.2013.3726

Hayes, J. F., Marston, L., Walters, K., King, M. B., and Osborn, D. P. J. (2017). Mortality gap for people with bipolar disorder and schizophrenia: UK-based cohort study 2000-2014. Br. J. Psychiatry 211, 175-181. doi: 10.1192/bjp.bp.117.202606.

Hayes, L., Hawthorne, G., Farhall, J., O’Hanlon, B., and Harvey, C. (2015). Quality of life and social isolation among caregivers of adults with schizophrenia: policy and outcomes. Community Ment. Health J. 51, 591-597. doi: 10.1007/s10597015-9848

Hesse, K., Kriston, L., Mehl, S., Wittorf, A., Wiedemann, W., Wölwer, W., et al. (2015). The vicious cycle of family atmosphere, interpersonal self-concepts, and paranoia in schizophrenia - a longitudinal study. Schizophr. Bull. 41, 1403-1412. doi: 10.1093/schbul/sbv055

Higgins, J. P. T., and Altman, D. G. (2008). "Assessing risk of bias in included studies," in Cochrane Handbook for Systematic Reviews of Interventions, eds J. P. T. Higgins and S. Green (Wiley), 187-241.

Honings, S., Drukker, M., ten Have, M., de Graaf, R., van Dorsselaer, S., and van Oscorresponding, J. (2017). The interplay of psychosis and victimisation across the life course: a prospective study in the general population. Soc. Psychiatry Psychiatr. Epidemiol. 52, 1363-1374. doi: 10.1007/s00127-017-1430-9

Howard, L. M. (2012). Domestic violence: its relevance to psychiatry. Adv. Psychiatr. Treat. 18, 129-136. doi: 10.1192/apt.bp.110.008110

Hsu, M. C., and Tu, C. H. (2013). Adult patients with schizophrenia using violence towards their parents: a phenomenological study of views and experiences of violence in parent-child dyads. J. Adv. Nurs. 70, 336-349. doi: 10.1111/jan. 12194

Hutton, P., Parker, S., Bowe, S., and Ford, S. (2012). Prevalence of violence risk factors in people at ultra-high risk of developing psychosis: a service audit. Early Interv. Psychiatry 6, 91-96. doi: 10.1111/j.1751-7893.2011.00307.x

Joyal, C. C., Côté, G., Meloche, J., and Hodgins, S. (2011). Severe mental illness and aggressive behaviour: on the importance of considering subgroups. Int. J. Forensic Ment. Health 10, 107-117. doi: 10.1080/14999013.2011.577136

Kageyama, M., Solomon, P., Kita, S., Nagata, S., Yokoyama, K., Nakamura, Y., et al. (2016). Factors related to physical violence experienced by parents of persons in Japan. Psychiatry Res. 243, 439-445. doi: 10.1016/j.psychres.2016.06.036

Kageyama, M., Yokoyama, K., Nagata, S., Kita, S., Nakamura, Y., Kobayashi, S., et al. (2015). Rates of family violence among patients with schizophrenia in Japan. Asia Pacific J. Public Health 27, 652-660 doi: 10.1177/1010539515595069

Kaplan, H. I., and Sadock, B. J. (1989). Comprehensive Textbook of Psychiatry IV. Baltimore, MD: Williams and Willkins.

Keers, R., Ullrich, S., DeStavola, B. L., and Coid, J. W. (2014). Association of violence with emergence of persecutory delusions in untreated schizophrenia. Am. J. Psychiatry 171, 332-339. doi: 10.1176/appi.ajp.2013.130 10134

Khalid, F. N., Ford, T., and Maughan, B. (2012). Aggressive behaviour and psychosis in a clinically referred child and adolescent sample. Soc. Psychiatry Psychiatr. Epidemiol. 47, 1795-1806. doi: 10.1007/s00127-012-0480-2

Kingston, C., Onwumere, J., Keen, N., Ruffell, T., and Kuipers, E. (2016). Post traumatic symptoms in caregivers of people with psychosis and associations with caregiving experiences. J. Trauma Dissoc. 17, 307-321. doi: 10.1080/15299732.2015.1089969

Kjellin, L., and Ostman, M. (2005). Relatives of psychiatric inpatientsdo physical violence and suicide attempts of patients influence family burden and participation in care? Nordic J. Psychiatry 59, 7-11. doi: 10.1080/08039480510018850

Kluiter, H., Kramer, J. J. A. M., and Wiersma, D. (1998). Interview for Measuring the Burden on the Family (IBF). Groningen: Department of Social Psychiatry, University of Groningen.

Kuipers, E., Onwumere, J., and Bebbington, P. (2010). A cognitive model of caregiving in psychosis. Br. J. Psychiatry 196, 259-265. doi: 10.1192/bjp.bp.109.070466

Large, M. M., and Nielssen, O. (2008). Evidence for a relationship between the duration of untreated psychosis and the proportion of psychotic homicides prior to treatment. Soc. Psychiatry Psychiatr. Epidemiol. 43, 37-44. doi: $10.1007 / \mathrm{s} 00127-007-0274-0$ 
Large, M. M., and Nielssen, O. (2011). Violence in first-episode psychosis: a systematic review and meta-analysis. Schizophr. Res. 125, 209-220. doi: $10.1016 /$ j.schres.2010.11.026

Lauber, C., Eichenberger, A., Luginbühl, P., Keller, C., and Rössler, W. (2003). Determinants of burden in caregivers of patients with exacerbating schizophrenia. Eur. Psychiatry 18, 285-289. doi: 10.1016/j.eurpsy.2003.06.004

Lefley, H. P. (1987). Impact of mental illness in families of mental health professionals. J. Nerv. Ment. Dis. 175, 613-619. doi: 10.1097/00005053-198710000-00006

Loughland, C. M., Lawrence, G., Allen, J., Hunter, M., Lewin, T. J., Oud, N. E., et al. (2009). Aggression and trauma experiences among carer-relatives of people with psychosis. Soc. Psychiatry Psychiatr. Epidemiol. 44, 1031-1040. doi: 10.1007/s00127-009-0025-5

McCann, T. V., Lubman, D. I., and Clark, E. (2011). First-time primary caregivers' experience of caring for young adults with first-episode psychosis. Schizophr. Bull. 37, 381-388. doi: 10.1093/schbul/sbp085

McGrath, J., Saha, S., Chant, D., and Welham, J. (2008). Schizophrenia: a concise overview of incidence, prevalence, and mortality. Epidemiol. Rev. 30, 67-76. doi: 10.1093/epirev/mxn001

Meehan, J., Flynn, S., Hunt, I. M., Robinson, J., Bickley, H., Parsons, R., et al. (2006). Perpetrators of homicide with schizophrenia: a national clinical survey in England and Wales. Psychiatr. Services 57, 1648-1651. doi: $10.1176 /$ ps.2006.57.11.1648

Moher, D., Liberati, A., Tetzlaff, J., Altman, D. G., and the PRISMA Group. (2009). Preferred reporting items for systematic reviews and meta-analyses: the PRISMA statement. Ann. Intern. Med. 151, 264-269. doi: 10.7326/0003-4819151-4-200908180-00135

Nederlof, A. F., Muris, P., and Hovens, J. E. (2011). Threat/control-override symptoms and emotional reactions to positive symptoms as correlates of aggressive behavior in psychotic patients. J. Nerv. Ment. Dis. 199, 342-347. doi: 10.1097/NMD.0b013e3182175167

NICE (National Institute for Health and Care Excellence) (2014). Psychosis and Schizophrenia in Adults: Prevention and Management. Clinical Guideline CG178 (Update) London: NICE.

NICE (National Institute for Health and Care Excellence) (2015). Violence and Aggression: Short-Term Management in Mental Health, Health and Community Settings. NICE Guideline NG10. London: NICE.

Nielssen, O., and Large, M. (2010). Rates of homicide during the first episode of psychosis and after treatment: a systematic review and meta-analysis. Schizophr. Bull. 36, 702-712. doi: 10.1093/schbul/sbn144

Nielssen, O., Westmore, B. D., Large, M. M., and Hayes, R. A. (2007). Homicide during psychotic illness in New South Wales between 1993 and 2002. Med. J. Aust. 186, 301-305.

Nordström, A., Dahlgren, L., and Kullgren, G. (2006). Victim relations and factors triggering homicides committed by offenders with schizophrenia. J. Forensic Psychiatry Psychol. 17, 192-203. doi: 10.1080/14789940600631522

Nordström, A., and Kullgren, G. (2003a). Victim relations and victim gender in violent crimes committed by offenders with schizophrenia. Soc. Psychiatry Psychiatr. Epidemiol. 38, 326-330. doi: 10.1007/s00127-003-0640-5

Nordström, A., and Kullgren, G. (2003b). Do violent offenders with schizophrenia who attack family members differ from those with other victims?. Int. J. Forensic Ment. Health 2, 195-200. doi: 10.1080/14999013.2003.10471191

Norman, R., Lecomte, T., Addington, D., and Anderson, E. (2017). CPA treatment guidelines on psychosocial treatment of schizophrenia in adults. Can. J. Psychiatry La Revue Canadienne de Psychiatrie 62, 617-623. doi: 10.1177/ 0706743717719894

Norman, R. M. G., Malla, A. K., Manchanda, R., Harricharan, R., Takhar, J., and Northcott, S. (2005). Social support and three-year symptom and admission outcomes for first episode psychosis. Schizophr. Res. 80, 227-234. doi: 10.1016/j.schres.2005.05.006

O’Brien, M. P., Gordon, J. L., Bearden, C. E., Lopez, S. R., Kopelowicz, A., and Cannon, T. D. (2006). Positive family environment predicts improvement in symptoms and social functioning among adolescents at imminent risk for onset of psychosis. Schizophr. Res. 81, 269-275. doi: 10.1016/j.schres.2005.10.005

O'Callaghan, C. E., and Richman, A. V. (2010). Violence in older people with mental illness. Adv. Psychiatr. Treat. 16, 339-348. doi: 10.1192/apt.bp. 108.006288
Onwumere, J., Glover, N., Whittaker, S., Rahim, S., Man, L. C., James, G., et al. (2017). Modifying illness beliefs in recent onset psychosis carers: evaluating the impact of a cognitively focused brief group intervention in a routine service. Early Interv. Psychiatry. doi: 10.1111/eip.12430. [Epub ahead of print].

Onwumere, J., Grice, S., Garety, P., Bebbington, P., Dunn, G., Freeman, D., et al. (2014). Caregiver reports of patient-initiated violence in psychosis. Can. J. Psychiatry 59, 376-384. doi: 10.1177/070674371405900705

Onwumere, J., Learmonth, S., and Kuipers, E. (2016). Caring for a relative with delusional beliefs. J. Psychiatr. Ment. Health Nurs. 23, 145-155. doi: $10.1111 /$ jpm.12291

Onwumere, J., Parkyn, G., Learmonth, S., and Kuipers, E. (2018). The last taboo: the experience of violence in first episode psychosis caregiving relationships. Psychol. Psychother. Theory Res. Pract. doi: 10.1111/ papt.12173

Oram, S., Flynn, S. M., Shaw, J., Appleby, L., and Howard, L. M. (2013). Mental illness and domestic homicide: a population-based descriptive study. Psychiatr. Services 64, 1006-1011. doi: 10.1176/appi.ps.201200484

Oud, N. E. (2001). "Testing the perception of prevalence of aggression scale (POPAS)," in Presentation at the 2nd European Congress on Violence in Clinical Psychiatry (Stockholm; Amsterdam).

Pai, S., and Kapur, R. L. (1981). The burden on the family of a psychiatric patient: development of an interview schedule. Br. J. Psychiatry 138, 332-335. doi: 10.1192/bjp.138.4.332

Palumbo, C., Volpe, U., Matanov, A., Priebe, S., and Giacco, D. (2015). Social networks of patients with psychosis: a systematic review. BMC Res. Notes 8:560. doi: 10.1186/s13104-015-1528-7

Patterson, P., Birchwood, M., and Cochrane, R. (2005). Expressed emotion as an adaptation to loss: prospective study in first-episode psychosis. Br. J. Psychiatry Suppl. 48, 59-64. doi: 10.1192/bjp.187.48.s59

Perlick, D. A., Hohenstein, J. M., Clarkin, J. F., Kaczynski, R., and Rosenheck, R. A. (2005). Use of mental health and primary care services by caregivers of patients with bipolar disorder: a preliminary study. Bipolar Disord. 7, 126-135. doi: 10.1111/j.1399-5618.2004. 00172.x

Platt, S., Weyman, A., Hirsch, S., and Hewett, S. (1980). The Social Behaviour Assessment Schedule (SBAS): rationale, contents, scoring and reliability of a new interview schedule. Soc. Psychiatry Psychiatr. Epidemiol. 15, 43-55. doi: 10.1007/BF00577960

Ran, M. S., Chui, C. H. K., Wong, I. Y.-L., Mao, W. J., Lin, F. R., Liu, B., et al. (2016). Family caregivers and outcome of people with schizophrenia in rural China: 14 year follow up study. Soc. Psychiatry Psychiatr. Epidemiol. doi: 10.1007/s00127-015-1169-0.

Revier, C. J., Reininghaus, U., Dutta, R., Fearon, P., Murray, R. M., Doody, G. A., et al. (2015). Ten-year outcomes of first-episode psychoses in the MRC AESOP-10 study. J. Nervous Ment. Dis. 203, 379-386. doi: 10.1097/NMD.0000000000000295

Shopp, R. F. (1996). Communicating risk assessments: accuracy, efficacy, and responsibility. Am. Psychol. 51, 939-944. doi: 10.1037/0003-066X.51.9.939

Short, T., Thomas, S., Mullen, P., and Ogloff, J. R. (2013). Comparing violence in schizophrenia patients with and without comorbid substanceuse disorders to community controls. Acta Psychiatr. Scand. 128, 306-313. doi: 10.1111/acps.12066

Smallwood, J., Jolley, J., Makhijania, J., Grice, S., O’Donoghue, E., Bendon, P., et al. (2017). Implementing specialist psychological support for caregivers in psychosis services: a preliminary report. Psychosis. 9, 119-128. doi: 10.1080/17522439.2016.1259647

Smith, L., Onwumere, J., Craig, T., and Kuipers, E. (2018). A role for poor sleep in determining distress in caregivers of individuals with early psychosis. Early Interv. Psychiatry. doi: 10.1111/eip.12538. [Epub ahead of print].

Solomon, P., Draine, J., and Delaney, D. (1995). The use of restraining orders by families of severely mentally ill adults. Adm. Policy Ment. Health 23, 157-161. doi: 10.1007/BF02106726

Solomon, P. L., Cavanaugh, M. M., and Gelles, R. J. (2005). Family violence among adults with severe mental illness: a neglected area of research. Trauma Violence Abuse 6, 40-54. doi: 10.1177/1524838004272464

Spidel, A., Lecomte, T., Greaves, C., Sahlstrom, K., and Yuille, J. C. (2010). Early psychosis and aggression: predictors and prevalence of violent behaviour 
amongst individuals with early onset psychosis. Int. J. Law Psychiatry 33, 171-176. doi: 10.1016/j.ijlp.2010.03.007

Stowkowy, J., Addington, D. L. L., Hollowell, B., and Addington, J. (2012). Predictors of disengagement from treatment in an early psychosis program. Schizophr. Res. 136, 7-12. doi: 10.1016/j.schres.2012.01.027

Straus, M. A., Hamby, S. L., Boney-McCoy, S., and Sugarman, D. B. (1996). The revised Conflict Tactics Scales (CTS2). J. Fam. Issues 17, 283-316. doi: 10.1177/019251396017003001

Strauss, J. S., and Carpenter, W. T. Jr. (1972). The prediction of outcome in schizophrenia. I. Characteristics of outcome. Arch. Gen. Psychiatry 27, 739-746. doi: 10.1001/archpsyc.1972.01750300011002.

Straznickas, K. A., McNiel, D. E., and Binder, R. L. (1993). Violence toward family caregivers by mentally ill relatives. Hospital Community Psychiatry 44, 385-387. doi: $10.1176 /$ ps.44.4.385

Sündermann, O., Onwumere, J., Kane, F., Morgan, C., and Kuipers, E. (2014). Social networks and support in first episode psychosis: exploring the role of loneliness and anxiety. Soc. Psychiatry Psychiatr. Epidemiol. 49, 359-366. doi: 10.1007/s00127-013-0754-3

Swanson, J. W., Swartz, M. S., Van Dorn, R. A., Elbogen, E. B., Wagner, R., Rosenheck, R. A., et al. (2006). A national study of violent behavior in persons with schizophrenia. Arch. Gen. Psychiatry. 63, 490-499. doi: 10.1001/archpsyc.63.5.490

Taylor, P. J. (2008). Psychosis and violence: stories, fears, and reality. Can. J. Psychiatry 53, 647-659. doi: 10.1177/070674370805301004

ten Have, M., de Graaf, R., van Weeghel, J., and van Dorsselaer, S. (2014). The association between common mental disorders and violence: to what extent is it influenced by prior victimization, negative life events and low levels of social support?. Psychol. Med. 44, 1485-1498. doi: 10.1017/S0033291713002262

The Schizophrenia Commission (2012). The Abandoned Illness: a report from the Schizophrenia Commission. London: Rethink Mental Illness.

Thompson, M. S. (2007). Violence and the costs of caring for a family member with severe mental illness. J. Health Soc. Behav. 48, 318-323. doi: 10.1177/002214650704800308

Ullrich, S., Keers, R., and Coid, J. (2013). Delusions, anger, and serious violence: new findings from the MacArthur violence risk assessment study. Schizophr. Bull. 40, 1174-1181. doi: 10.1093/schbul/sbt126

Ural, C., Belli, H., Öncü, F., and Soysal, H. (2012). Profile of population targeted by violent behavior of psychotic patients. Turkish J. Psychiatry 23, 26-32.

Vaddadi, K. S., Gilleard, C., and Fryer, H. (1997). Abuse of carers by relatives with severe mental illness. Int. J. Soc. Psychiatry 48,149-155. doi: $10.1177 / 002076402128783208$

Vaddadi, K. S., Gilleard, C., and Fryer, H. (2002). Abuse of carers by relatives with severe mental illness. Int. J. Soc. Psychiatry 48, 149-155.
Varghese, A., Khakha, D. C., and Chadda, R. K. (2016). Pattern and type of aggressive behavior in patients with severe mental illness as perceived by the caregivers and the coping strategies used by them in a tertiary care hospital. Arch. Psychiatr. Nurs. 30, 62-69. doi: 10.1016/j.apnu.2015. 10.002

Vaughn, C., and Leff, J. (1976). The measurement of expressed emotion in the families of psychiatric patients. Br. J. Soc. Clin. Psychol. 15, 157-165. doi: 10. 1111/j.2044-8260.1976.tb00021.x

Weiss, D. S., and Marmar, C. R. (1997). “The impact of event scale-revised," in Assessing Psychological Trauma and PTSD: a practitioner's handbook. eds J. P. Wilson, and T. M. Keane (New York, NY: Guilford Press), 399-411.

Whiteford, H. A., Degenhardt, L., Rehm, J., Baxter, A. J., Ferrari, A. J., Erskine, H. E., et al. (2013). Global burden of disease attributable to mental and substance use disorders: findings from the Global Burden of Disease Study 2010. Lancet 382, 1575-1586. doi: 10.1016/S0140-6736(13)61611-6

Winsper, C., Singh, S. P., Marwaha, S., Amos, T., Lester, H., Everard, L., et al. (2013). Pathways to violent behaviour during first episode psychosis. A report from the UK national EDEN study. J. Am. Med. Assoc. 70, 1287-1293. doi: 10.1001/jamapsychiatry.2013.2445

Witt, K., van Dorn, R., and Fazel, S. (2013). Risk factors for violence in psychosis: systematic review and meta-regression analysis of 110 studies. PLOS ONE 8:e55942. doi: 10.1371/journal.pone.0055942

World Health Organisation (2002). World Report on Violence and Health: Summary. Geneva: World Health Organization.

World Health Organization (2018). Schizophrenia. Geneva: World Health Organization. Available online at: http://www.who.int/mental_health/ management/schizophrenia/en/ (Accessed 31st March, 2018).

Yudofsky, S. C., Silver, J. M., Jackson, W., Endicott, J., and Williams, D. (1986). The overt aggression scale for the objective rating of verbal and physical aggression. Am. J. Psychiatry. 143, 35-39. doi: 10.1176/ajp. 143.1 .35

Conflict of Interest Statement: The authors declare that the research was conducted in the absence of any commercial or financial relationships that could be construed as a potential conflict of interest.

Copyright (c) 2018 Onwumere, Zhou and Kuipers. This is an open-access article distributed under the terms of the Creative Commons Attribution License (CC BY). The use, distribution or reproduction in other forums is permitted, provided the original author(s) and the copyright owner(s) are credited and that the original publication in this journal is cited, in accordance with accepted academic practice. No use, distribution or reproduction is permitted which does not comply with these terms. 